\title{
¿ES NECESARIA EN EUROPA UNA ESTRATEGIA PARA LA ECONOMIA COLABORATIVA?
}

\author{
Alvaro San Martin Rodriguez \\ Alumno de doctorado, Universidad de León, \\ Visitante Académico Centro de Estudios Socio-Legales, \\ Universidad de Oxford (Hillary Term, 2019)
}

\begin{abstract}
El derecho fundamental a unas condiciones justas y equitativas en el trabajo podría no alcanzarse dentro del modelo de negocio de la economía colaborativa y es la Unión Europea la llamada buscar una solución. La falta de unas claras iniciativas normativas de cara a afrontar las amenazas laborales que este nuevo modelo económico genera implica que sean los Tribunales de los distintos países miembros los que tengan que resolverlas a golpe de sentencia. Una estrategia europea para la economía colaborativa podría suponer el impulso definitivo que garantice un escenario pacífico y rentable en este nuevo modelo de negocio.
\end{abstract}

The fundamental right to fair and just working conditions may not be achieved within the collaborative economy business model and it is the European Union called to find a solution. The lack of clear normative initiatives in order to face the labor threats that this new economic model generates implies that the different Courts from the member states have to resolve this by sentences. A European strategy for the collaborative economy could mean the definitive momentum that guarantees a peaceful and profitable scenario in this new business model.

Title: Is a Strategy on the Collaborative Economy necessary in Europe?

Palabras clave: Economía colaborativa, estrategia, autónomos, plataformas digitales, estabilidad, política europea.

Keywords: Collaborative economy, strategy, autonomous, digital platforms, stability, European politics

IUSLabor 3/2019, ISSN 1699-2938, p. 81-113

DOI.10.31009/IUSLabor.2019.i03.04

Fecha envío: 20.10.2019 | Fecha aceptación: 13.11.2019 


\section{Sumario}
1. Introducción
2. Polémicas y soluciones en Europa
3. Aportaciones de la doctrina
4. Conclusiones
5. Bibliografía 


\section{Introducción}

La economía colaborativa, junto a las nuevas tecnologías (el sector más grande del mundo en términos de capitalización de mercado, solo por detrás de las finanzas ${ }^{1}$ ), ha desarrollado en los últimos años un avance de tal magnitud que ha llamado poderosamente la atención de las instituciones y la comunidad académica internacional y europea.

En lo que se refiere a la propia definición de economía colaborativa, no existe un claro consenso. Esta depende, principalmente, de la perspectiva desde la cual sea observada: la sharing economy hace referencia a un escenario socioeconómico en el que son compartidos recíprocamente y sin una necesaria contraprestación económica determinados bienes de cualquier naturaleza (creación producción distribución consumo); el término gig economy es usado en aquella perspectiva de la economía colaborativa que es utilizada como medio de vida gracias a plataformas qué proveen trabajos con amplia flexibilidad y la llamada peer-to-peer es aplicada a organizaciones y plataformas donde se intercambian servicios sin intermediarios ${ }^{2}$.

Sin embargo, lo más adecuado, a los efectos de encontrar una definición lo más aproximada posible a la realidad, es tomar como referencia aquella señalada desde las instituciones europeas. La Comisión Europea ha definido el término de economía colaborativa como "modelos de negocio en los que se facilitan actividades mediante plataformas colaborativas que crean un mercado abierto para el uso temporal de mercancías o servicios ofrecidos a menudo por particulares. La economía colaborativa implica a tres categorías de agentes i) prestadores de servicios que comparten activos, recursos, tiempo y/o competencias —pueden ser particulares que ofrecen servicios de manera ocasional ('pares') o prestadores de servicios que actúen a título profesional ('prestadores de servicios profesionales'); ii) usuarios de dichos servicios; y iii) intermediarios que - a través de una plataforma en línea-conectan a los prestadores con los usuarios y facilitan las transacciones entre ellos ('plataformas colaborativas'). Por lo general, las transacciones de la economía colaborativa no implican un cambio de propiedad y pueden realizarse con o sin ánimo de lucro" ${ }^{3}$.

\footnotetext{
${ }^{1}$ Prueba de ello es que la mitad de las diez empresas más importantes del mundo tienen su actividad principal en esta industria, según es indicado en PWC, Global Top 100 Companies by market capitalisation, 2017 ,

en https://preview.thenewsmarket.com/Previews/PWC/DocumentAssets/477067.pdf, p. 4.

${ }^{2}$ STRoKes, K. et alii: Making sense of the UK Collaborative Economy, Nesta, Londres, 2014, p. 10, en https://collaborativeeconomy.com/wp/wp-

content/uploads/2015/04/making_sense_of_the_uk_collaborative_economy_14.pdf

${ }^{3}$ Comisión Europea: Comunicación de la comisión al parlamento europeo, al consejo, al comité económico y social europeo y al comité de las regiones; una agenda europea para la economía
} 
Al margen de las probadas ventajas que supone este modelo de negocio para el desarrollo de un país en determinados sectores como el turismo, finanzas o transporte, las lagunas legales existentes en muchos de los estados de la Unión Europea avocan a que los conflictos laborales originados tengan que ser resueltos a golpe de sentencia. Según la Comisión de Mercado Interior y Protección del Consumidor del Parlamento Europeo, en lo que respecta a los derechos laborales de los trabajadores implicados en estos modelos de negocio colaborativos, existe un "riesgo real de que tenga lugar un menoscabo de las condiciones de trabajo justas, las normas jurídicas mínimas y la protección social adecuada" 4 .

Por ello, el presente artículo pretende exponer las amenazas que la economía colaborativa o gig economy (desde el punto de vista del trabajo en este modelo de negocio) ha presentado en los países en los que ha tenido más desarrollo, así como las soluciones propuestas por estos. Serán observadas, además de estas respuestas, las recomendaciones de la doctrina y de las instituciones para valorar si finalmente existe la necesidad de establecer un marco regulatorio común que establezca unas pautas a seguir por todos los estados en la búsqueda de armonía de derechos en este modelo de negocio.

\section{Polémicas y soluciones en Europa}

Para valorar el impacto que supone la economía colaborativa en los países miembros de la Unión Europa es necesario observar los resultados del trabajo financiado por la Comisión Europea y publicado en febrero de 2018, titulado "Estudio para monitorear el desarrollo económico de la economía colaborativa a nivel sectorial en los 28 Estados

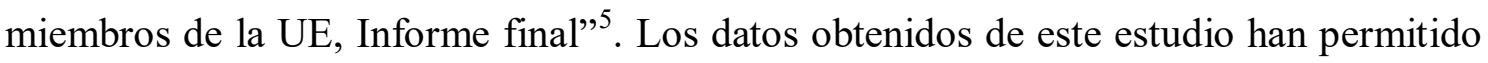
valorar la implicación de la economía colaborativa en Europa y el desarrollo que ha tenido en cada uno de sus estados miembros en función de las respuestas de sus gobiernos.

En este sentido, en términos de empleo, del análisis tanto de las plataformas como de los propios proveedores de servicios se ha estimado que este modelo de negocio proporciona aproximadamente 394.000 puestos de trabajo en toda la Unión Europea. Los sectores donde más oportunidades de empleo existen son el sector del transporte (124.800 personas empleadas) y el que menos el sector financiero (67.300 empleados).

\footnotetext{
colaborativa,

2016 https://eur-lex.europa.eu/legalcontent/EN/TXT/HTML/?uri=CELEX:52016DC0356\&from=ES, p. 3.

${ }^{4}$ PARLAMENTO EUROPEO: Informe sobre una Agenda Europea para la economía colaborativa, 2017, en http://www.europarl.europa.eu/doceo/document/A-8-2017-0195_EN.pdf, pág. 16.

${ }^{5}$ Comisión Europea: Study to Monitor the Economic Development of the Collaborative Economy at sector level in the 28 EU Member States, 2018, en https://publications.europa.eu/en/publication-detail//publication/0cc9aab6-7501-11e8-9483-01aa75ed71a.
} 
La siguiente figura representa la distribución del empleo total por países en millones de personas:

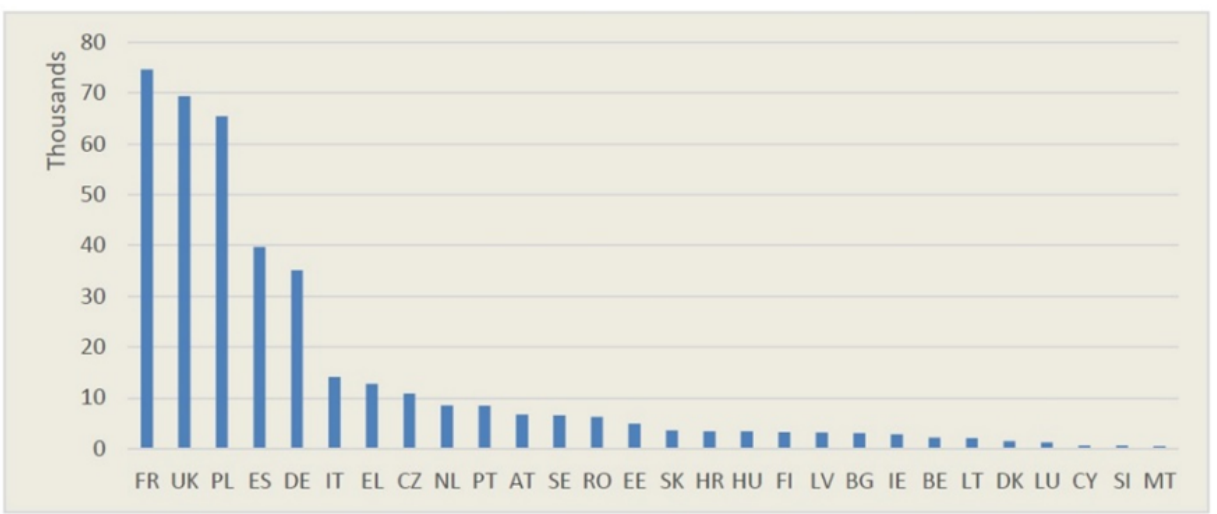

Figura 1. Fuente: Study to Monitor the Economic Development of the Collaborative Economy at sector level in the 28 EU Member States

Es observado que los países que han tomado medidas para eliminar las barreras del mercado se encuentran en una posición más beneficiosa de desarrollo de este modelo de negocio (República Checa, Francia), por el contrario "cuando los gobiernos son más bien neutrales y el entorno empresarial no es tan alentador, la economía colaborativa parece desarrollarse a un ritmo más lento" (Bulgaria, Eslovenia) ${ }^{6}$. También es necesario tener presente la manifiesta fragmentación reglamentaria sobre la materia resultante de enfoques reguladores divergentes a nivel local o nacional que existen en los distintos estados y que, según la Comisión Europea, "dificulta el desarrollo de la economía colaborativa en Europa e impide la plena materialización de sus beneficios"”. Estos obstáculos, unidos al aumento progresivo del empleo, abocan a que los desequilibrios en derechos surgidos en este modelo desemboquen en conflictos laborales difícilmente evitables.

Con todo esto, y para realizar una aproximación al panorama social y legal existente en Europa sobre la implicación de la economía colaborativa en el tejido laboral, el autor ha realizado una breve síntesis de los conflictos registrados en los 28 países miembros de la Unión Europea y las principales demandas expuestas en cada uno de ellos. Desde el análisis genérico y aproximado de las principales polémicas manifiestas en los países miembros, ha podido observarse dos principales indicios. El primero es que no en todos los países miembros han sido manifestados conflictos por las condiciones laborales de los trabajadores implicados en este modelo económico. El segundo es que en aquellos

\footnotetext{
${ }^{6}$ COMISIÓn EUROPEA: Study to Monitor the Economic Development of the Collaborative Economy at sector level in the 28 EU Member States, cit., p. 159.

${ }^{7}$ Comisión EuRopea: Study to Monitor the Economic Development of the Collaborative Economy at sector level in the 28 EU Member States, cit., p. 2.
} 
países en que sí han sido registrados, el sector predominante y originario de las demandas es el sector transportes, y en particular, las empresas de entrega de comida a domicilio (principalmente en Francia, España y Reino Unido) demandando una clasificación de sus contratos de trabajo. La siguiente figura representa una aproximación de las polémicas registradas por el autor y demandas para su solución en los países miembros de la zona Euro.

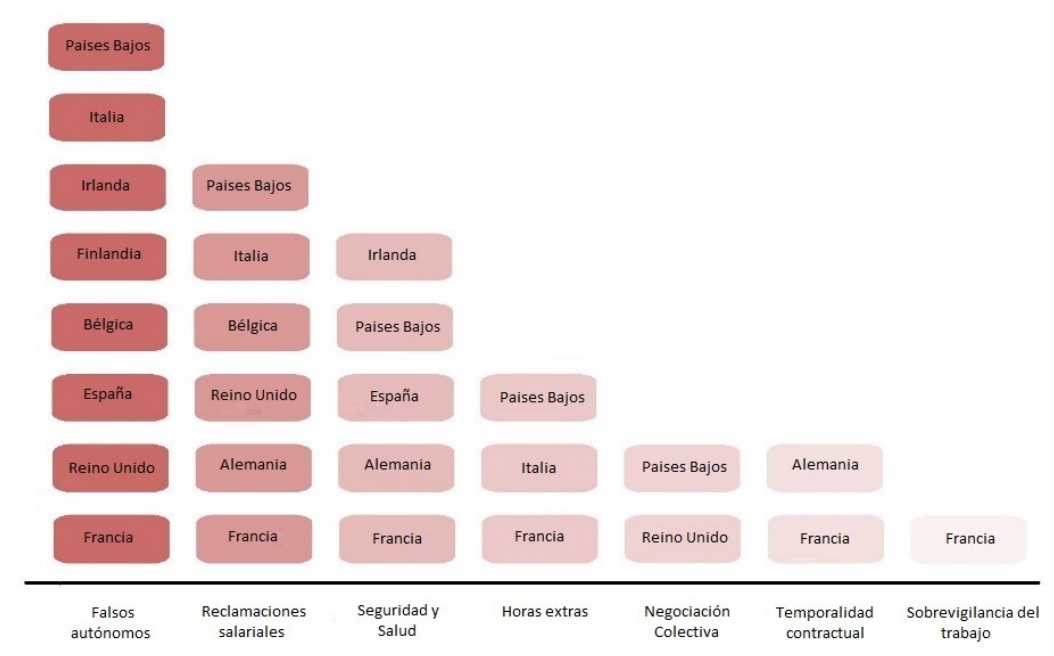

Figura 2. . Polémicas y demandas registradas por el autor en distintos países miembros de la Unión Europea. Fuente: elaboración propia.

Es preciso indicar que en muchos de los países analizados no ha sido registrada ninguna polémica debido al leve impacto cultural y a la amplia brecha existente entre las regiones urbanas y rurales que existe en este modelo de negocio (como Rumania o Austria, por ejemplo). Sin embargo, al mismo tiempo, es observado que, principalmente, el mayor registro de conflictividad laboral coincide con países en los que mayor desarrollo ha tenido la economía colaborativa.

En Francia, el país donde más impacto ha tenido este modelo de negocio, las primeras protestas laborales por las condiciones de trabajo en las plataformas digitales, según ha podido registrarse, surgieron desde la sede de Chalon-sur-Saône de la plataforma americana Amazon, dedicada a la venta de servicios y productos tradicionales a través de internet, tras 12 años después de su llegada al país (septiembre 2000). Estas, fueron por parte de trabajadores asalariados, relativas a excesos de vigilancia y monitorización de su proceso productivo, imposición de horas extraordinarias, frecuente rotación y 
dificultades para el pago de las bajas por enfermedad, entre otros motivos ${ }^{8}$. El motivo más preocupante, y que generó la convocatoria de una huelga el 26 de mayo de 2015, fueron las estadísticas de sus accidentes de trabajo ${ }^{9}$. Desde entonces, y especialmente desde la proliferación de los servicios de mensajería de comida a domicilio, en Paris no han dejado de sucederse protestas de los trabajadores repartidores contra las plataformas digitales que los contratan ${ }^{10}$.

En el Reino Unido, desde la llegada de Amazon, a mediados de los años 2000 en Gales, han existido protestas de los trabajadores de esta plataforma relativas a políticas salariales, representación sindical y negociación colectiva que han continuado con denuncias por las condiciones de trabajo en plataformas de otros sectores ${ }^{11}$. También en el sector del transporte, los trabajadores freelanders a tiempo parcial de la empresa Deliveroo UK, secundaron protestas por las nuevas condiciones de pago que intento imponer la empresa (al intentar pasar de tarifas de cobro por horas a tarifas de cobro por entrega), y a gracias a ello —y a la presión por parte del gobierno - consiguieron no sólo que la empresa retirara la medida, sino que además les pagara el salario mínimo interprofesional al que no tenían derecho por no estar en la plantilla ${ }^{12}$.

También en este país han sido polémicas las protestas relativas a las condiciones de trabajo, principalmente de los trabajadores de la plataforma Uber. En octubre de 2016, un Tribunal Laboral de Reino Unido señaló que sus conductores no eran trabajadores por cuenta propia y que debían ser clasificados como trabajadores por cuenta ajena con derecho al salario mínimo interprofesional. Dos años más tarde, en diciembre de 2018, la Corte de Apelación de Inglaterra y Gales (División Civil), inadmite la apelación interpuesta por Uber y confirma la sentencia del Tribunal inferior, señalando un "alto grado de ficción" en el contenido del acuerdo estándar entre Uber y sus conductores.

\footnotetext{
${ }^{8}$ VION-DURY, P: “tu travailles à amazon? oh, mon pauvre. tu tiens le coup?", web: nouve lobs [en línea], [fecha de consulta: 20/10/2019], Disponible en: https://www.nouvelobs.com/rue89/rue89economie/20140320.RUE2786/tu-travailles-a-amazon-oh-mon-pauvre-tu-tiens-le-coup.html.

9 BRIGAND, M.: "Quand Amazon s'arrange avec les accidents de travail”, Web: Le Figaro [en línea], [Fecha de consulta: 20/10/2019], disponible en: http://www.lefigaro.fr/secteur/hightech/2015/05/22/32001-20150522ARTFIG00258-quand-amazon-s-arrange-avec-les-accidents-detravail.php?redirect_premium.

${ }^{10}$ SANSOM, A.: "Bicycle couriers protest against takeaway food service Deliveroo", Web: France 24 [en línea], [Fecha de consulta: 20/10/2019], disponible en: https:/www.france24.com/en/20170812-franceparis-protest-food-delivery-service-deliveroo-financial-insecurity-emmanuel-macron

${ }^{11}$ BBC NEws: "GMB union holds protests at Amazon sites", Web: BBC News [en línea], [Fecha de consulta: 20/10/2019], disponible en: https://www.bbc.com/news/uk-21444710

${ }^{12}$ SINGH, A.: "Deliveroo agrees to pay workers $£ 7$ an hour after wage protests", Web: The Independent [en línea], [Fecha de consulta: 20/10/2019], disponible en: https://www.independent.co.uk/news/business/news/deliveroo-wages-protests-agrees-to-pay-workers-7an-hour-after-protests-against-wages-overhaul-a7190071.html
} 
Según la sentencia, "para que ULL (Uber London Limited) declare a su regulador estatutario que está operando un servicio privado de vehículos de alquiler en Londres, y que es una persona idónea para hacerlo, al mismo tiempo que argumenta en este el litigio de que es simplemente un afiliado de una compañía holandesa registrada que autoriza a decenas de miles de propietarios de pequeñas empresas a usar su software, lo cual contribuye al aire de artificio y artificialidad que impregna el caso de Uber “13.

En Alemania, el sindicato Vereinte Dienstleistungsgewerkschaft (Sindicato de Servicios de Alemania, o mejor conocido como ver.di), ha liderado diversas protestas y demandas desde el año 2012 en las que son criticadas la alta tasa de temporalidad que existen en los contratos, los bajos salarios y la baja protección por accidentes de trabajo entre otros motivos $^{14}$. Las protestas, desde sus inicios, se han enfocado, principalmente, en denunciar la falta de estabilidad laboral en la empresa y la necesidad de mejorar las condiciones de trabajo ${ }^{15}$, llegando incluso a proponer una huelga en diciembre de 2018 con el fin de hacer cumplir estas demandas y obtener un adecuado convenio pactado a través de la negociación colectiva ${ }^{16}$.

En este país también han existido importantes protestas de trabajadores de empresas como Foodora o Deliveroo (plataformas digitales de entrega de comida a domicilio) quienes demandan mejoras salariales $y$ en las condiciones de trabajo ${ }^{17}$. Las agrupaciones extraoficiales de los llamados bikers (o repartidores que trabajan para estas plataformas en el estatus indicado) cada vez son más activas y demandan una negociación colectiva adecuada en la que se puedan negociar mejoras en las condiciones

\footnotetext{
${ }^{13}$ Sentencia del Tribunal de Apelación (División Civil) sobre la apelación del Tribunal de Empleo del Reino Unido, 30 de octubre de 2018 (Uber B.V. \& Ors v Aslam \& Ors), en http://www.bailii.org/ew/cases/EWCA/Civ/2018/2748.html

${ }^{14}$ HASBerg, M.: "Gewerkschaft klagt über Lohndumping bei Amazon”, Web: Welt [en línea], [Fecha de consulta: 20/10/2019], disponible en: https://www.welt.de/wirtschaft/article11688472/Gewerkschaftklagt-ueber-Lohndumping-bei-Amazon.html.

15 Sponholz, K.: "Beschäftigte beklagen mieses Arbeitsklima bei Amazon", Web: Westfälische Rundschau, [en línea], [Fecha de consulta: 20/10/2019], disponible en: https://www.wr.de/region/westfalen/beschaeftigte-beklagen-mieses-arbeitsklima-bei-amazonid7064258.html

${ }^{16}$ REUTERS: "Verdi funkt Amazon im Weihnachtsgeschäft mit Streik dazwischen", Reuters [en línea], [Fecha de consulta: 20/10/2019], disponible en: https://de.reuters.com/article/deutschland-amazonidDEKBN1OG0U1

${ }^{17}$ Haswell, J.: "Foodora and Deliveroo couriers protest working conditions in Berlin", Web: The Local [en línea], [Fecha de consulta: 20/10/2019], disponible en: https://www.thelocal.de/20170518/foodoraand-deliveroo-couriers-protest-working-conditions-in-berlin
} 
de trabajo a efectos salariales, organización, liquidación de horas, materiales puestos a disposición por la empresa, así como una negociación de un convenio colectivo ${ }^{18}$.

En España, la británica Deliveroo, ha sido objeto de numerosas denuncias ante la Inspección de Trabajo por utilizar contratos fraudulentos de su llegada en noviembre de 2015. Los sindicatos, desde la llegada de estas empresas de transporte como Glovo ${ }^{19}$, Deliveroo, Uber Eats o Stuart, vienen denunciado el uso de determinadas prácticas fraudulentas en la contratación de su personal. En concreto, señalan que estas establecen una relación laboral encubierta, en fraude de ley, a través de la figura de falsos autónomos, organizando la distribución y ejecución del trabajo de sus contratados, imponiendo un régimen sancionador riguroso, estableciendo unilateralmente los precios de los pedidos, aportando la infraestructura fundamental de la empresa para poder realizar la actividad y formando a sus trabajadores en métodos de trabajo, comportamiento y vestimenta. Todos estos elementos han llevado a la Inspección de Trabajo de Valencia a confirmar las denuncias, caracterizando este tipo de relación como una verdadera relación laboral por cuenta ajena encubierta ${ }^{20}$.

La empresa Uber Systems Spain S.L., filial de la norteamericana Uber Technologies Inc., también ha sido investigada por las condiciones laborales de sus empleados. La investigación realizada por la Inspección de Trabajo de Cataluña recoge en su informe de 9 de marzo de 2015, al que tuvo acceso el diario El País, que existen notas de dependencia y ajenidad en los contratos de esta empresa con sus conductores. En esta se observa que estos "carecen de cualquier tipo de organización empresarial, quedando inscritos ab initio a la estructura y organización [de la empresa Uber]" y además "disfrutan de una libertad de horario, pero como contrapartida están sujetos a un sistema de productividad" 21 .

En Turín (Italia) en 2016 se produjeron las primeras movilizaciones del país de trabajadores de economía colaborativa. Las protestas se fundamentaron principalmente

\footnotetext{
${ }^{18}$ LehmanN, H: "Fahrradkuriere von Deliveroo und Foodora stellen Forderungen", Web: Tagesspiegel [en línea], [Fecha de consulta: 20/10/2019], disponible en: https://digitalpresent.tagesspiegel.de/fahrervon-foodora-und-deliveroo-organisieren-sich

${ }^{19}$ En esta empresa, sin la participación de los sindicatos, los propios trabajadores han apoyado huelgas y protestas para denunciar sus condiciones de trabajo, EL PERIODICO: "Huelga colaborativa' contra Glovo en Zaragoza: sus repartidores colapsan la app en hora punta", 2018, en https://www.elperiodico.com/es/economia/20180911/trabajadores-glovo-zaragoza-colapsan-app-protestalaboral-7028233

${ }^{20}$ UGT: "Denuncia de UGT sobre plataformas digitales en Dirección General de Trabajo", 2017, en http://www.ugt.es/Publicaciones/denuncia\%20plataformas\%20digitales.pdf

${ }^{21}$ Gozzer, S.: "Trabajo dice que los chóferes de Uber son empleados de la firma", Web: El Pais [en línea], [Fecha de consulta: 20/10/2019], disponible en: https://elpais.com/economia/2015/06/12/actualidad/1434135569_865496.html
} 
en la asunción de costes de mantenimiento de la actividad por parte de la empresa Foodora respecto de los mensajeros y el aumento de las tarifas por hora que les abonaban $^{22}$.

En Bélgica, también han sido registradas protestas de similar naturaleza, relativas a bajos salarios ${ }^{23}$ e inadecuada clasificación como trabajadores autónomos, como también ocurrió en los Países Bajos ${ }^{24}$.

El sindicato PAM, en Finlandia, lleva tiempo alertando de la necesidad de regular las relaciones de los trabajadores autónomos, ya que podría contaminar a otras profesiones $^{25}$, y concentra sus esfuerzos en publicitar sus servicios a este tipo de trabajadores $^{26}$. En Irlanda, por otro lado, es la seguridad en el trabajo lo que preocupa a los propios mensajeros ${ }^{27}$.

Polonia, durante los últimos años ha registrado manifiestas las demandas promovidas desde los sindicatos en materia de negociación colectiva, privacidad y monitorización del trabajo, condiciones del lugar de trabajo, la intensificación del trabajo, el equilibrio trabajo-vida, nuevas cargas o pérdida de puestos de trabajo por automatización e informatización para los trabajadores de la economía colaborativa en Polonia ${ }^{28}$.

Dentro de este hostil panorama han podido registrarse las distintas tendencias resolutorias planteadas por los distintos países de cara a eliminar los conflictos. Según el análisis llevado a cabo por el autor, ha podido observarse que, la clasificación profesional inadecuada de trabajadores autónomos sigue siendo no solo la principal

${ }^{22}$ TASSINARI A. Y MACCARRONE, V: "The mobilisation of gig economy couriers in Italy: some lessons for the trade union movement", Transfer, Vol. 23, 2017, núm. 3, p. 353-357.

${ }^{23}$ SHENKER, J: "Strike 2.0: how gig economy workers are using tech to fight back", Web: The Guardian [en línea], [Fecha de consulta: 20/10/2019], disponible en: https://www.theguardian.com/books/2019/aug/31/the-new-resistance-how-gig-economy-workers-arefighting-back.

${ }^{24}$ CASSAUWERS, T.: "In Europe, food delivery coops are fighting back against the gig economy", 2018, en https://www.equaltimes.org/in-europe-food-delivery-coops-are?lang=es\#.XZFA_kYzZPZ.

25 YleSRADIO: "Gig economy transforms Finnish labor", 2019, en https://yle.fi/uutiset/osasto/news/gig_economy_transforms_finnish_labour/10844347

${ }^{26}$ DøLVIK, J.E. Y JESNES. K.: Nordic labour markets and the sharing economy, Nordic Council of Ministers, 2017, en https://norden.diva-portal.org/smash/get/diva2:1072087/FULLTEXT02.pdf.

${ }^{27}$ CUNNINGHAM, O.: "TERROR ON STREETS Deliveroo riders strike in Dublin to protest recent spate of violent assaults by teenagers”, Web: The Sun [en línea], [Fecha de consulta: 20/10/2019], disponible en: https://www.thesun.ie/news/3787988/deliveroo-riders-strike-dublin-attacks/

28 Voss, E. Y RiEDE H.: “Cyfryzacja A Partycypacja Pracowników: Jakie są opinie związków zawodowych, pracowników na poziomie przedsiębiorstwa i pracowników wykonujących pracę za pośrednictwem platform cyfrowych w Europie", Confederación Europea de Sindicatos, Bruselas, 2018, en https://www.etuc.org/sites/default/files/publication/file/2018-09/Voss\%20Report\%20PL1.pdf 
polémica, sino también la principal respuesta regulatoria que suelen dar los gobiernos de los países, según la siguiente figura

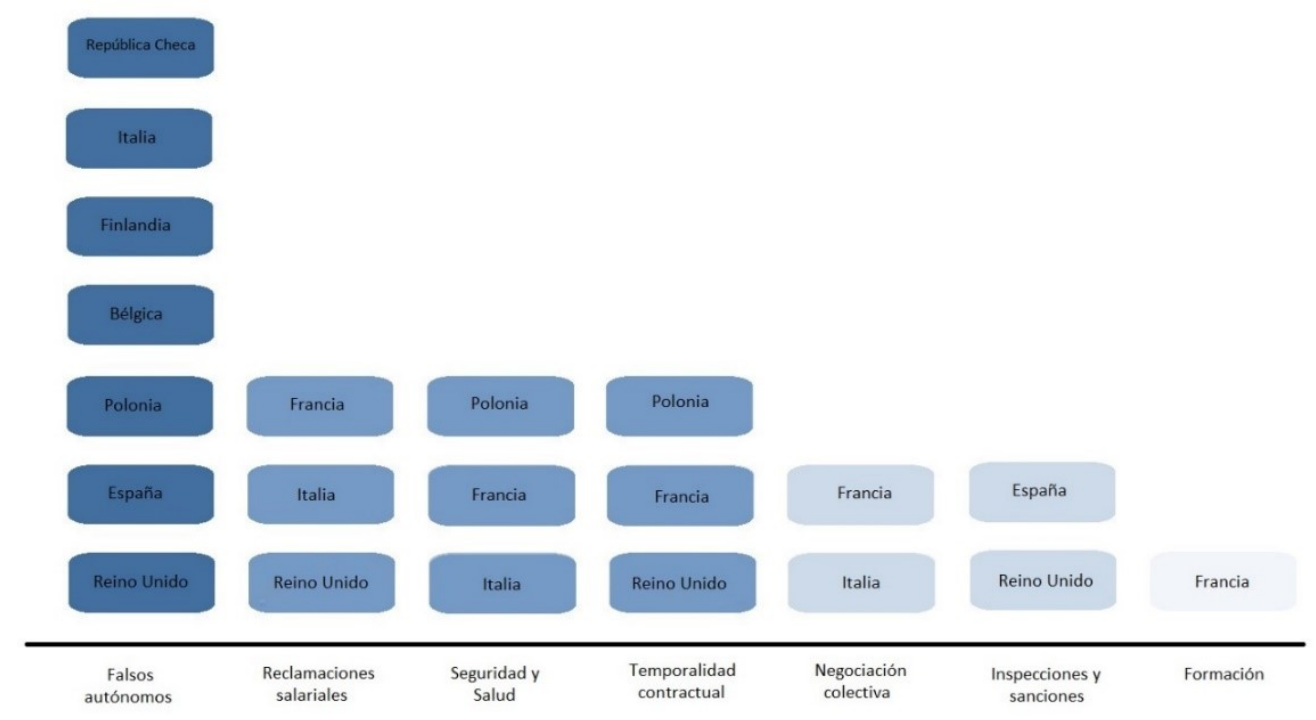

Figura 3. Orientaciones regulatorias de los países miembros como respuesta a las demandas de los trabajadores de la economía colaborativa. Fuente: elaboración propia.

En este sentido, los países que mayor iniciativa regulatoria han tenido coinciden no solamente con aquellos en los que han sido registrados la mayor parte de los conflictos, sino también con aquellos en los que la economía colaborativa ha tenido un mayor desarrollo.

Siguiendo la línea de protección laboral que exigen las instituciones europeas, Francia ha sido el país en Europa que ha impulsado una de las mayores intervenciones regulatorias sobre este modelo de negocio. En la legislación laboral se ha facilitado la integración del concepto de economía colaborativa y su modelo de negocio. A través del Ley núm. 2016-1088, de 8 de agosto de 2016, sobre el trabajo, la modernización del diálogo social y la obtención de trayectorias profesionales, se introdujo un nuevo título dentro del Código Laboral (artículo L.7341-1 del Código del Trabajo) que define las plataformas de colaboración por referencia al artículo 242 bis del Código Fiscal General ("empresas, cualquiera que sea el lugar de su ubicación, que ponen en contacto a distancia y por vía electrónica a dos personas para la venta de un bien, la prestación de un servicio o el intercambio o la compartición de un servicio"). Los artículos que 
siguen en ese capítulo de responsabilidad social de las plataformas incorporan garantías genéricas en materia de seguros de accidentes, formación, huelga y asociación.

Posteriormente el Decreto núm. 2017-774 del 4 de mayo de 2017 en relación con la responsabilidad social de las plataformas de conexión por medios electrónicos, concreta más estas garantías genéricas introduciendo los artículos D7342-1 y siguientes, donde se especifica la existencia de una responsabilidad por parte de las plataformas colaborativas de asumir la contribución de seguros que cubran el riesgo de accidentes en el trabajo y formación profesional cuando un trabajador autónomo suscrito a ellas realiza una cifra de trabajo igual o superior a $13 \%$ del techo anual de la seguridad social.

Casi un año después de la publicación de este decreto se inscribe en la asamblea nacional, el 27 de abril de 2018, el proyecto de Ley por la Libertad de Elegir el Futuro Profesional, el cual, tras más de dos meses de debate y 2500 enmiendas analizadas, es aprobado el 1 de agosto de 2018. Entre las medidas introducidas, las más significativas son: la protección por un subsidio de 800 euros de los trabajadores autónomos en caso de quiebra de la compañía; controles en las estadísticas de los contratos temporales; mejora de la prestación por desempleo; focalización de la formación en cuanto a su financiación por parte del gobierno y a la mejora de su calidad a través del control de un organismo público creado ex profeso para ello (France Skill); la creación de una aplicación digital y un sistema de "Compte Personnel de Formation" o Cuenta Personal de Formación, para el seguimiento de la formación del trabajador a través de la aplicación; el aumento de las sanciones por precariedad laboral (multas que ascienden de 2.000 a 4.000 euros por diferencias salariales, así como publicación web en una lista publica de empresas que utilizan tácticas ilegales); abre la puerta a la posibilidad de establecer un "estatuto" o "carta" que defina los derechos y obligaciones hacia los trabajadores, y viceversa.

En España, en comparación con otros países, no se han registrado formalmente avances significativos en la regulación de esta figura más allá de reformas impositivas a las grandes empresas para evitar el fraude fiscal ${ }^{29} \mathrm{y}$ de varias proposiciones de ley sin ningún tipo de resultado.

En diciembre del año 2017, la Comisión de Empleo y Seguridad Social del Congreso aprobó por unanimidad una proposición no de ley en la que instaba al Gobierno a identificar las reformas necesarias a realizar en la normativa laboral con respecto a la economía colaborativa, de cara "a los desafíos del cambio tecnológico sobre nuestro

\footnotetext{
${ }^{29}$ Servulo GonZalez, J.: "Hacienda pretende gravar más a plataformas como Airbnb y Uber", Web: El Pais [en línea], [Fecha de consulta: 20/10/2019], disponible en: https://elpais.com/economia/2018/10/04/actualidad/1538646576_607775.html
} 
sistema productivo, así como a las plataformas digitales y a sus usuarios", haciendo especial referencia al trabajo por cuenta propia y por cuenta ajena ${ }^{30}$. En junio del año 2018, el PP llevo al Pleno del Congreso otra proposición de ley con el objeto de buscar conductas que atenten contra los derechos de los trabajadores en las empresas que utilicen el modelo de negocio de la economía colaborativa y especialmente sobre la polémica que rodea la figura del colaborador, dando especial protagonismo a la inspección de trabajo ${ }^{31}$.

A través de una enmienda transaccional a la misma, los partidos PSOE, Ciudadanos y PDeCAT coincidieron en reclamar en el Pleno del Congreso la creación de un grupo de trabajo en el Gobierno para estudiar con los agentes sociales las reformas necesarias para adaptar la normativa al nuevo modelo de negocio de las plataformas digitales ${ }^{32}$. Sin embargo, a día de hoy se ha registrado la creación del mismo o de ninguna propuesta encaminada a este fin por parte de cualquier partido político dentro de los programas electorales presentados para las elecciones generales a celebrar en el mes de noviembre de 2019.

En Reino Unido, los agentes más vulnerables del sector del transporte dentro de la economía colaborativa, los llamados Cycle couriers, a mediados del año 2016 comenzaron batallas legales para reclamar condiciones de trabajo dignas y el reconocimiento de su condición de empleados contra las empresas Excel, City Sprint, Addison Lee and eCourier (estas utilizan este modelo de negocio tomando como referencia plataformas digitales).

Los tribunales sentenciaron contra todas las empresas que los Cycle Couriers no son trabajadores autónomos, sino que son empleados de las compañías y deberían disfrutar de todos los derechos como tal. Según el tribunal, los trabajadores "se encontraban bajo la dirección de otro y no dirigían su propio negocio", y no sólo bajo esa circunstancia, sino que "durante el tiempo que [el trabajador] se registraba en el sistema por la mañana hasta el momento en el que se desconectaba, la relación de trabajo, considerada en

\footnotetext{
${ }^{30}$ EUROPA PRESS: "El Congreso pide al Gobierno que estudie cómo adaptar el marco laboral a la economía digital", Web: Europa Press [en línea], [Fecha de consulta: 20/10/2019], disponible en: https://www.europapress.es/economia/laboral-00346/noticia-congreso-pide-gobierno-estudie-adaptarmarco-laboral-economia-digital-20171213191451.html

${ }^{31}$ Europa Press: "El PP lleva al Pleno del Congreso la precariedad de los 'falsos autónomos' en empresas como Deliveroo", Web: Europa Press [en línea], [Fecha de consulta: 20/10/2019], disponible en: https://www.europapress.es/economia/laboral-00346/noticia-pp-lleva-pleno-congreso-precariedadfalsos-autonomos-empresas-deliveroo-20180621150238.html

${ }^{32}$ LA VANGUARDIA: "PP, PSOE y Cs piden estudiar con sindicatos y patronal cómo adaptar la ley laboral a la economía digital", Web: La Vanguardia [en línea], [Fecha de consulta: 20/10/2019], disponible en: https://www.lavanguardia.com/vida/20180626/45424884357/economia--pp-psoe-y-cs-piden-estudiarcon-sindicatos-y-patronal-como-adaptar-la-ley-laboral-a-la-economia-digital.html
} 
conjunto, sólo era compatible con su condición de trabajador en la "limb b"; se conoce a los trabajadores "limb b" como personas que trabajan por cuenta propia y prestan sus servicios como parte de una profesión o empresa comercial llevada a cabo por otra persona $^{3334}$.

Después de estas transcendentes sentencias sobre las condiciones de los Cycling Couriers, de las recomendaciones del informe realizado por Matthew Taylor ${ }^{35}$ (consideradas como escasas por parte de algunos sectores sindicales ${ }^{36}$ ) y de la polémica generada por el fallecimiento de un trabajador de DPD (Don Lane, un mensajero autónomo para DPD que no asistió a citas médicas para tratar a su diabetes), las condiciones de trabajo de los empleados en la economía colaborativa han cobrado una especial relevancia en Reino Unido, donde el gobierno ha direccionado una estrategia política encaminada a la garantía de derechos laborales en este modelo de negocio. Según la primera ministra Theressa May, es preciso "asegurarnos de que tenemos las estructuras correctas para reflejar esos cambios" $" 37$.

Después de prometer mejoras durante todo el año 2018 en asuntos de temporalidad, regulaciones de los trabajadores autónomos, y pago de vacaciones, el 17 de diciembre de 2018 el Departamento de Negocios, Energía y Estrategia Industrial, presentó el

\footnotetext{
${ }^{33}$ Sentencia del Tribunal de Apelación (División Civil) sobre la apelación del Tribunal de Empleo del Reino Unido, 10 de Febrero de 2017 (Pimlico Plumbers y Anor vs. Smith), en https://www.employmentcasesupdate.co.uk/site.aspx?i=ed35083

${ }^{34}$ Sentencia del Tribunal de Empleo del Centro de Londres, 21 de marzo de 2017, (Boxer vs. Excel Group Services Ltd), en https://assets.publishing.service.gov.uk/media/58ecacb5ed915d06ac000150/Mr_A_Boxer_v_Excel_Grou p_Services_Ltd_in_liquidation_3200365-2016_Final_and_Reasons.pdf

${ }^{35}$ Este informe fue encargado por la primera ministra Theresa May con el objetivo de revisar las condiciones de trabajo de los trabajadores de las plataformas debido al impacto social que las recientes decisiones y protestas sindicales habían provocado, en BOOTH, R.: "Low-paid workers need better job satisfaction, No 10 review will say", Web: The Guardian [en línea], [Fecha de consulta: 20/10/2019], disponible en: https://www.theguardian.com/society/2017/jul/07/low-paid-workers-job-satisfaction-no10-review-taylor-report; SWINFORD, S.: "Theresa May paves way for self-employed and temporary workers to be protected by new laws", Web: The Telegraph [en línea], [Fecha de consulta: 20/10/2019], disponible en: https://www.telegraph.co.uk/news/2016/09/30/theresa-may-paves-way-for-self-employedand-temporary-workers-to/

${ }^{36}$ MOYER-LEE, J.: "Wishy-washy and full of fluff - the Taylor review offers Little", Web: The Guardian [en línea], [Fecha de consulta: 20/10/2019], disponible en: https://www.theguardian.com/commentisfree/2017/jul/18/taylor-review-gig-economy-workers.

${ }^{37}$ Воотн, R.: "Gig economy workers angry at lack of bogus self-employment curbs", Web: The Guardian [en línea], [Fecha de consulta: 20/10/2019], disponible en: https://www.theguardian.com/business/2018/feb/07/gig-economy-workers-angry-at-lack-of-bogus-selfemployment-curbs
} 
"Good Work Plan" ${ }^{38}$, un paquete de reformas laborales que "consolidará el estatus del Reino Unido como líder mundial en los derechos de los trabajadores ahora y en el futuro, y será el primer país del mundo en abordar las oportunidades y los desafíos de la economía del trabajo y el mundo cambiante del trabajo, y su impacto en un economía moderna" "39. Entre estas propuestas, a aplicar en el año 2019, se incluyen más recursos para la Inspección de Estándares de la Agencia de Empleo (EAS), nuevas facultades para imponer multas a los empleadores que incumplan la legislación de las agencias de empleo, como la falta de pago de salarios; trabajadores vulnerables, horas de trabajo asalariado y planes de sacrificio salarial para garantizar las normas nacionales de salario mínimo.

En Italia desde el comienzo de las protestas en Turín en octubre del 2016 las necesidades regulatorias en la economía colaborativa han estado en primera línea en el debate político. Desde entonces, han sido numerosas las asambleas legislativas de las distintas regiones del país que han aprobado o impulsado propuestas legislativas en esta materia tomando como núcleo del debate las regulaciones sobre el estatus de los trabajadores por cuenta propia (Región de Piamonte, la Región de Toscana, el Municipio de Nápoles, la Región de Emilia-Romaña y la Región de Umbría) ${ }^{40}$. En junio del año 2018 el por entonces a líder del movimiento 5 estrellas y actual ministro de Asuntos Exteriores de Italia después de haberse reunido con una delegación de riders señaló la necesidad mejorar condiciones de los riders relativas a salarios y estatus contractuales de los trabajadores ${ }^{41}$.

En Polonia, a pesar de existir un propio ministerio en el gobierno de Polonia dedicado expresamente a la digitalización ${ }^{42}$, en Polonia no se ha llevado a cabo expresamente la

\footnotetext{
38 Department For Business, Energy \& Industrial Strategy, Good work plan, 2018, en https://assets.publishing.service.gov.uk/government/uploads/system/uploads/attachment_data/file/766167 /good-work-plan-command-paper.pdf

${ }^{39}$ Department For Business, ENERGy \& IndUSTRIAl StRATEgy, Largest upgrade in a generation to workplace rights - getting work right for British workers and businesses, 2018, en https://www.gov.uk/government/news/largest-upgrade-in-a-generation-to-workplace-rights-getting-workright-for-british-workers-and-businesses

${ }^{40}$ Bollettino Ufficiale Della Regione Umbria: "Proposta di legge alle camere 'Disposizioni in materia di lavoro mediante piattaforme digitali'”, 2019, en https:/inapp.org/sites/default/files/NORMATIVA/2019/Regionale/UM_DAL\%20n.315\%20del\%201903-19.PDF

${ }^{41}$ Politi, J: "Di Maio takes aim at Italy's gig economy", Web: Financial Times [en línea], [Fecha de consulta: 20/10/2019], disponible en: https://www.ft.com/content/04b6d97c-7305-11e8-aa3131da4279a601

${ }^{42}$ Responsable de la política estatal en el campo de la informatización, el desarrollo de servicios electrónicos de administración pública, la seguridad civil en el ciberespacio, la infraestructura y el uso de
} 
construcción de un marco regulatorio orientado a este nuevo modelo de negocio. Han sido aprobadas en el año 2016 normativas relativas a reducir el abuso hacia los trabajadores no estándares "para reducir la asimetría en términos de contratación y despido de trabajadores empleados con contratos permanentes y otros tipos de contratos" y normativas relativas a equiparar las normas de cobertura del seguro social de los trabajadores conforme a la ley civil (y también para equiparar) los contratos de comisión con las normas aplicables en la provisión de empleo con arreglo a los contratos de trabajo basados en el código laboral. Estas disposiciones "reducen la posibilidad de contratar empleados no estándar con un contrato base muy bajo cubierto por el seguro social y lo combinan con otro con una base más alta, no cubierto por el seguro social" 43 .

En Bélgica, las regulaciones de la economía colaborativa se han enfocado en modificaciones fiscales de la actividad y especialmente de normas específicas aplicables a los trabajadores por cuenta ajena y por cuenta propia del sector, pero únicamente desde el punto de vista fiscal. Por otro lado, la preocupación de Finlandia por el avance de la economía colaborativa no ha llegado a implicar algún tipo de modificación regulatoria, sino más bien medidas experimentales como la aplicación infructuosa de un experimento de renta básica universal motivado principalmente por la inestabilidad contractual en la economía colaborativa ${ }^{44}$.

En la República Checa no existe todavía ninguna regulación expresa sin embargo se ha hablado de que una de las principales barreras para su desarrollo es la regulación existente en el país en materia de trabajadores autónomos ya que la definición de esta figura es bastante imprecisa y podría dificultar el desarrollo ${ }^{45}$.

Por todo ello, es observado que en la mayoría de los países son las reclamaciones sobre la indebida calificación contractual de los trabajadores autónomos, los accidentes de trabajo y las diferencias salariales los principales motivos de las demandas, así como de las soluciones propuestas en los distintos países. Es evidente la presencia del conflicto, el interés por parte de los Estados en resolverlo y de la ausencia de una regulación desde

tecnologías modernas, cuyo gerente es Marek Zagórski, ver https://www.premier.gov.pl/ludzie/marekzagorski.html

${ }^{43}$ Comision Europea, Second Phase Consultation of Social Partners under Article 154 TFEU on a possible action addressing the challenges of access to social protection for people in all forms of employment in the framework of the European Pillar of Social Rights, 2017, en https://ec.europa.eu/social/BlobServlet?docId=18596\&langId=en, p. 158.

${ }^{44}$ PETER, L.: "No plans to expand Finland basic income trial", Web: BBC [en línea], [Fecha de consulta: 20/10/2019], disponible en: https://www.bbc.com/news/world-europe-43866700

${ }^{45}$ Comision Europea: Study to Monitor the Economic Development of the Collaborative Economy at sector level in the 28 EU Member States, cit., p. 87. 
Europa que dirija principios comunes regulatorios en aras al equilibrio de derechos en el presente modelo (a pesar de los evidentes avances normativos de algunos países como Francia, a la cabeza de Europa en la regulación de la economía colaborativa).

Con todo esto paradójicamente, las instituciones europeas no dejan de recomendar una regulación proteccionista de cara a los trabajadores implicados en el modelo de la economía colaborativa. A continuación, son señaladas las algunas preocupaciones de las principales instituciones europeas puestas de manifiesto a través de distintos instrumentos:

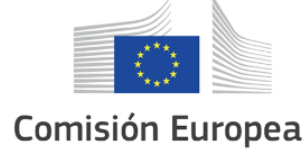

"Puede crear

incertidumbre en cuanto a los derechos aplicables y el nivel de protección social [pues] la frontera entre trabajadores por cuenta propia y por cuenta ajena es cada vez más difusa, y hay un aumento del trabajo temporal y a tiempo parcial, y del pluriempleo" $^{, 46}$

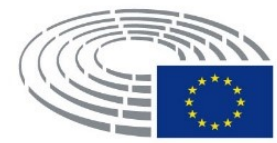

Parlamento Europeo

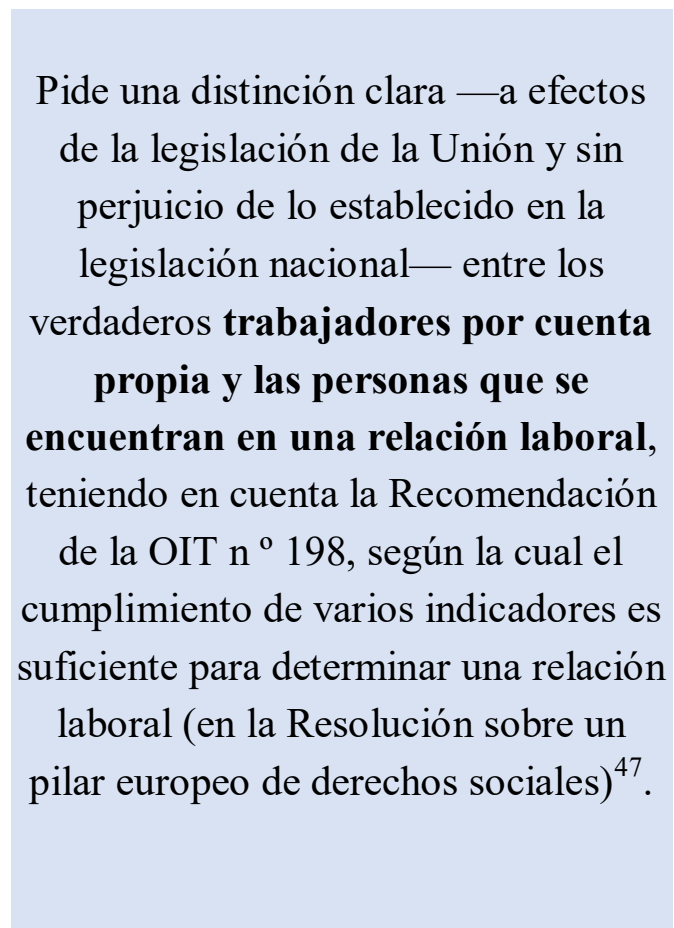

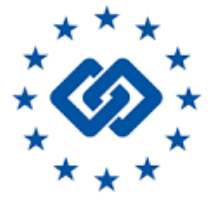

Eurofound

Señala que
"estas formas
de empleo (...)
que representan
un peligro
inherente para
las condiciones
de trabajo y el
mercado
laboral deben
abordarse a
través de la
legislación o la
regulación"
(Estudio $^{4015)^{48}}$.

${ }^{46}$ COMisión EuROPEA: Comunicación de la comisión al parlamento europeo, al consejo, al comité económico y social europeo y al comité de las regiones; una agenda europea para la economía colaborativa, cit., p. 11.

47 Parlamento EuROPEO: "Resolución del Parlamento Europeo, de 19 de enero de 2017, sobre un pilar europeo de derechos sociales", 2017, en http://www.europarl.europa.eu/sides/getDoc.do?pubRef=//EP//TEXT+TA+P8-TA-2017-0010+0+DOC+XML+V0//EN, p. 32.

48 MANDL, I. et alii: New forms of employment, 2015, en https://www.eurofound.europa.eu/sites/default/files/ef_publication/field_ef_document/ef1461en.pdf, p. 144. 


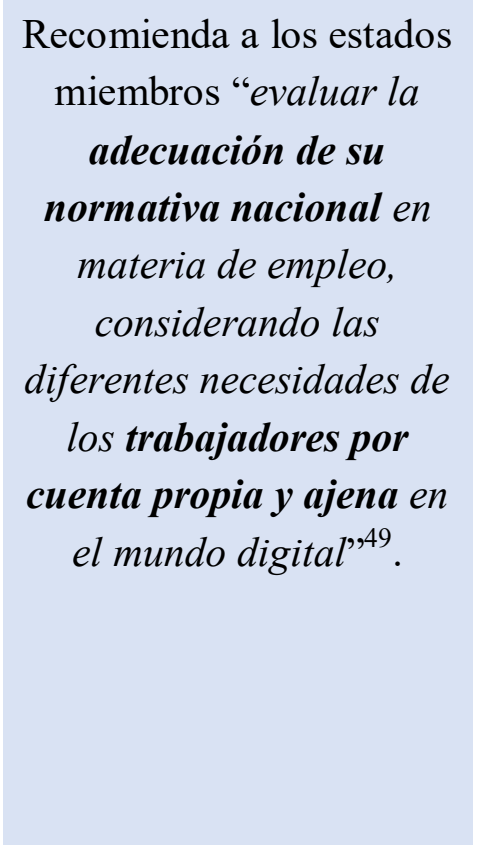

Señala los tres principales objetivos políticos son: cobertura (garantizar que todas las personas con empleo o autoempleadas tengan acceso formal y efectivo a la protección social y los servicios de empleo relacionados); transferibilidad (preservar los derechos de protección social cuando los trabajadores cambian de trabajo, sectores de actividad, formas de empleo,

Señala que "este desarrollo [de la
economía colaborativa] también
puede conducir a situaciones
precarias (...) [ y es preciso] prevenir
el autoempleo falso y garantizar la
protección de los derechos sociales y
laborales de todos los trabajadores en
la economía de plataforma,
independientemente de su estado
oficial como empleados o por cuenta
propia". También establece la
necesidad de garantizar que los
"trabajadores autónomos y
profesionales (...) reciban una
remuneración de nivel profesional y
tengan garantizados plazos de pago
seguros" (Informe en una Agenda
Europea para la economía colaborativa
(2017/2003 (INI))

El parlamento pide a los Estados miembros que realicen suficientes inspecciones de trabajo con respecto a las plataformas en línea e impongan sanciones en caso de incumplimiento de las normas, especialmente en lo que respecta a las condiciones de trabajo y empleo y los requisitos específicos relativos a las cualificaciones (Informe en una Agenda Europea para la economía colaborativa (2017/2003 (INI));

${ }^{49}$ COMISIÓN EUROPEA: Comunicación de la comisión al parlamento europeo, al consejo, al comité económico y social europeo y al comité de las regiones; una agenda europea para la economía colaborativa, cit., pág. 11. 


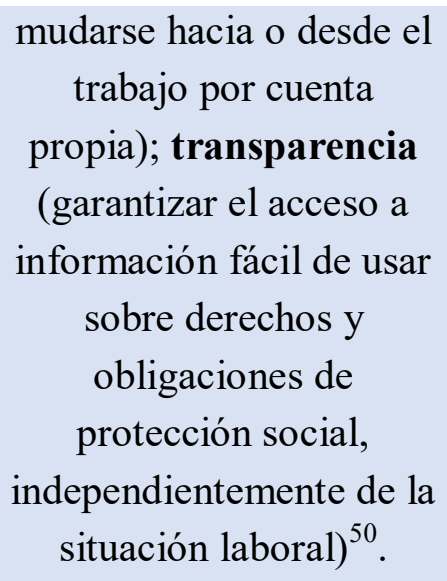

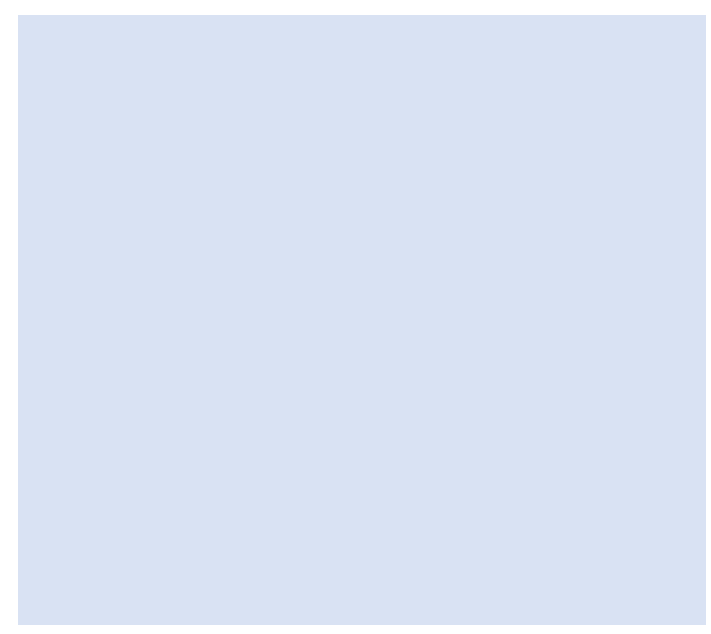

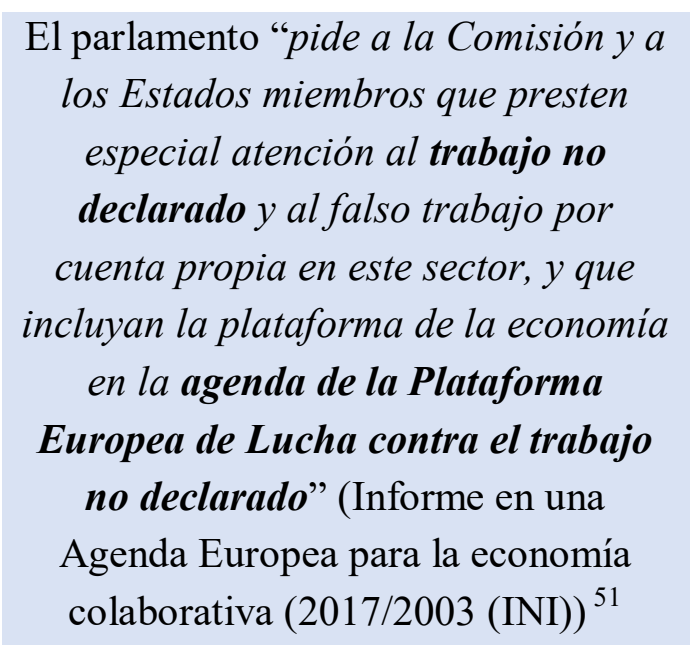

Figura 4. Alertas y recomendaciones de instituciones de la Unión Europea relativas a los trabajadores de la economía colaborativa.

Además, al margen de estas medidas proyectadas directamente desde las instituciones europeas, existen equipos de investigación e informes encargados por estas que también advierten de la especial vulnerabilidad de los trabajadores autónomos. Es señalado que, entre otros, los trabajadores están expuestos a accidentes laborales, falta de cobertura de seguros y prestaciones que están externalizado al trabajador, falta de agrupaciones

\footnotetext{
${ }^{50}$ Comisión Europea, Commission Staff Working Document, Analytical Document, Accompanying the document Consultation Document (Second Phase Consultation of Social Partners under Article 154 TFEU on a possible action addressing the challenges of access to social protection for people in all forms of employment in the framework of the European Pillar of Social Rights), 2017, en https://ec.europa.eu/social/BlobServlet?docId=18596\&langId=en, p. 3.

${ }^{51}$ PARLAMENTO EUROPEO: Informe sobre una Agenda Europea para la economía colaborativa, cit.
} 
laboral, inmediatez que exige el trabajo "en demanda", altas penalizaciones por mecanismos de calificación de los trabajadores cuestionables ${ }^{52}$.

\section{Aportaciones de la Doctrina}

Tras un minucioso análisis realizado por el autor de los contenidos doctrinales publicados en los últimos cinco años referidos a los derechos laborales en la economía colaborativa a nivel europeo e internacional, ha podido observarse que existen -especialmente en la literatura europea-- dos vertientes distintas en cuanto a las respuestas que precisan las amenazas sobre los derechos laborales que este nuevo modelo de negocio produce en Europa.

Siempre desde el equilibrio "entre facilitar el desarrollo tecnológico robótico y proteger los valores que son deseados por los humanos" 53 , pueden observarse criterios dispares en cuanto a una mayor o menor flexibilidad en la intervención regulatoria de cara a la protección de los derechos de los trabajadores en la economía colaborativa. Por un lado, se sitúan los defensores de la inversión en políticas de desarrollo del modelo de economía colaborativa, teniendo en cuenta y respetando los derechos de los trabajadores, pero dando prioridad a la flexibilidad en la regulación, y por otro se postulan los abiertamente defensores de una estricta intervención regulatoria de los poderes públicos en favor de la garantía de los derechos laborales, que son la gran mayoría.

Algunos autores de la primera corriente defienden, por ejemplo, que "en lugar de la ley laboral, sería más eficiente apoyar a los trabajadores directamente a través de la política social, adaptándose a las necesidades cambiantes de los trabajadores y de aquellos que se beneficiarian de sus habilidades" 54 . Se centran en el desarrollo de políticas activas en capacitación de competencias digitales, para que, en un "marco jurídico adecuado (...), los avances tecnológicos no se constituyan ni se conciban como

\footnotetext{
${ }^{52}$ SCHMID-DRÜNER, M.: "The situation of workers in the collaborative economy", Parlamento Europeo, Bruselas, 2016 , 2016, en http://www.europarl.europa.eu/RegData/etudes/IDAN/2016/587316/IPOL_IDA(2016)587316_EN.pdf.

${ }^{53}$ SÁNCheZ-URÁn AZAÑA, Y. Y GRAU RuiZ, M.A.: "El impacto de la robótica, en especial la robótica inclusiva, en el trabajo: aspectos jurídico-laborales y fiscales", Blog: Plataforma Digital Interuniversitaria sobre el Futuro del Derecho del Trabajo OIT [en línea], [Fecha de consulta: 20/10/2019], disponible en: https://iniciativaoitinteruniversitariafuturodeltrabajo.com/ver-articulos/item/el-impacto-de-la-robotica-enespecial-la-robotica-inclusiva-en-el-trabajo-aspectos-juridico-laborales-y-fiscales.

${ }^{54}$ Information TeChnology And InNOvation Foundation: "Three Paths to Update Labor Law for the Gig Economy", Information Technology \& Innovation Foundation, Washington, 2016, en http://www2.itif.org/2016-labor-law-gig-economy.pdf?_ga=2.219725593.1271927154.15545983131835988216.1554598313
} 
una afrenta a los derechos laborales (...) [y] los limites [en su regulación] no [sean] de tal calado que, en realidad, supongan impedir el avance mismo" 55.

Por otra parte, la segunda y mayoritaria corriente, alertando del crecimiento de la desigualdad $^{56}$ es partidaria de una estricta intervención regulatoria en este modelo de negocio para garantizar los derechos laborales, defendiendo el aumentar la "protección de los trabajadores sin aumentar repentinamente los costes de las plataformas" 57. Entre las medidas planteadas aparece la del establecimiento de un salario mínimo en función del promedio de finalización de una tarea $u$ horas trabajadas ${ }^{58}$ o la implantación de la obligatoriedad de contratación de un seguro de responsabilidad civil para terceros ${ }^{59}$. También se propone "la reforma en profundidad del sistema de formación para el empleo (...), inclusión de cláusulas de permanencia y de cláusulas de no competencia para después de la extinción del contrato de trabajo (...), un mecanismo de regulación del tiempo de trabajo (...), una mayor propensión al teletrabajo por parte de las empresas del sector TIC (...), tratamiento colectivo de los salarios en el sector" 60 .

Dentro de esta corriente están integrados la mayor parte de los actores sindicales que se pronuncian sobre el tema. Algunos de ellos defienden medidas como la desincentivación y penalización de la temporalidad injustificada del empleo, la mejora de las cualificaciones y la formación, la potenciación de las capacidades institucionales de las Administraciones Públicas en sus diferentes ámbitos territoriales o la mejora la negociación colectiva (medida en la que prácticamente todos los actores sindicales europeos coinciden $\left.{ }^{61}\right)^{62}$.

\footnotetext{
${ }^{55}$ San Martín MazzuCCONI, C.: "Generalización Tecnológica: efectos sobre las condiciones de trabajo y empleo", Blog: Plataforma Digital Interuniversitaria sobre el Futuro del Derecho del Trabajo OIT [en línea], [Fecha de consulta: 20/10/2019], disponible en: https://www.ilo.org/wcmsp5/groups/public/--europe/---ro-geneva/---ilo-madrid/documents/article/wcms_548618.pdf., p. 8.

${ }^{56}$ SCHMID-DRÜNER, M.: "The situation of workers in the collaborative economy", cit.

${ }^{57}$ Codagnone, C., Abadie, F. Y Biagi, F.: The Future of Work in the 'Sharing Economy', Market Efficiency and Equitable Opportunities or Unfair Precarisation, Comisión Europea, Bruselas, 2016, en http://publications.jrc.ec.europa.eu/repository/bitstream/JRC101280/jrc101280.pdf., p. 8.

${ }^{58}$ BERG, J.: "Income security in the on-demand economy: Findings and policy lessons from a survey of crowdworkers", OIT, Ginebra, 2016, en https:/www.ilo.org/wcmsp5/groups/public/---ed_protect/--protrav/---travail/documents/publication/wcms_479693.pdf., p. 23.

${ }^{59}$ VALENDUC, G Y VENDRAMIN, P.: Work in the digital economy: sorting the old from the new, Instituto Sindical Europeo, Bruselas, 2016, p. 46.

${ }^{60}$ Rodríguez Fernández, M.L., Y Pérez Del Prado, D.: Economía digital: su impacto sobre las condiciones de trabajo y empleo. Estudio de caso sobre dos empresas de base tecnológica, Fundación para el Diálogo Social, Madrid, 2017, en http://fdialogosocial.org/public/upload/2/23_FdS_Economiadigital-impacto-condiciones-trabajo-y-empleo_2017_final.pdf., p. 70.

${ }^{61}$ El profesor BAYLOS GRAU, en línea con las interpretaciones de la OIT, propone la necesidad de extender la acción sindical a sujetos cuyo trabajo no se inserta dentro del círculo del trabajo asalariado,
} 
Con todo, parece ser que la mayoría de la literatura legal independientemente de la pertenencia a una corriente u otra, más o menos flexible en cuanto a la regulación normativa de este modelo de negocio, tiene siempre presente el abuso del contrato de trabajador autónomo por parte de las plataformas digitales. Además de otras consecuencias como la vulneración de privacidad en las relaciones laborales ${ }^{63}$ o notas de precariedad $^{64}$, la preocupación por la vulnerabilidad de los trabajadores autónomos tiene un consenso asentado como el perjuicio más manifiesto de la economía colaborativa $^{65}$.

Con todo esto, una breve imagen puede sintetizar las diferentes corrientes y soluciones apoyadas, las cuales divergen en un punto común que es la protección de los derechos.

pensando en figuras como trabajadores por cuenta propia, en BAYLOS, A.: "El futuro de las normas del trabajo que queremos", Blog: Plataforma Digital Interuniversitaria sobre el Futuro del Derecho del Trabajo OIT [en línea], [Fecha de consulta: 20/10/2019], disponible en: https://iniciativaoitinteruniversitariafuturodeltrabajo.com/ver-articulos/item/el-futuro-de-las-normas-deltrabajo-que-queremos, p. 11.

${ }^{62}$ ROCHA, F.: "La Digitalización y el Empleo Decente en España: Retos y propuestas de actuación”, Blog: Plataforma Digital Interuniversitaria sobre el Futuro del Derecho del Trabajo OIT [en línea], [Fecha de consulta: 20/10/2019], disponible en: https://www.ilo.org/madrid/fow/trabajo-decente-paratodos/WCMS_548595/lang--es/index.htm, p. 12.

${ }^{63}$ MCDOnald, P y ThOMPSOn, P.: "Social Media(tion) and the Reshaping of Public/Private Boundaries in Employment Relations", International Journal of Management Reviews, Vol. 18, núm. 1, 2015, págs. 6984, en https://onlinelibrary.wiley.com/doi/epdf/10.1111/ijmr.12061

${ }^{64}$ Huws, U., SPEncer, N. H. Y Syrdal, D.: "Online, on call: the spread of digitally organised just-intime working and its implications for standard employment models", New Technology, Work and Emplyment, Vol. 33, núm. 8, 2018, p. 113-129, en https://uhra.herts.ac.uk/bitstream/handle/2299/20891/Huws_et_al_2018_New_Technology_Work_and_E mployment.pdf? sequence $=1$ \&isAllowed $=\mathrm{y}$

${ }^{65}$ COMISIÓN EUROPEA: Study to Monitor the Economic Development of the Collaborative Economy at sector level in the 28 EU Member States, cit. , pág. 11. También en la doctrina, CHERRY, M.: "Beyond Misclassification: The Digital Transformation of Work", Comparative Labor Law \& Policy Journal, Vol. 37, 2016, p. 577-602, en https://scholarship.law.slu.edu/cgi/viewcontent.cgi?article=1009\&context=faculty; TODOLí SIGNES, A.: "El impacto de la 'uber economy' en las relaciones laborales: los efectos de las plataformas virtuales en el contrato de trabajo", Iuslabor, núm. 3, 2015, págs. 1699-2938; PRASSL,J. Y RiSAK, M.: "Uber, Taskrabbit, \& Co: Platforms as Employers? Rethinking the legal analysis of Crowdwork", Comparative Labor Law \& Policy Journal, Vol. 37, núm. 3, 2016, p. 604-619; MatSAGANIS, M. et alii: Non-standard employment and access to social security benefits, Comisión Europea, Bruselas, 2016, en http://ec.europa.eu/social/BlobServlet?docId=15687\&langId=en; SPASOvA, S. et alii: Access to social protection for people working on non-standard contracts and as self-employed in Europe, Comisión Europea, Bruselas, 2017, en https:/publications.europa.eu/en/publication-detail/-/publication/fb235634e3a7-11e7-9749-01aa75ed71a1/language-en. 


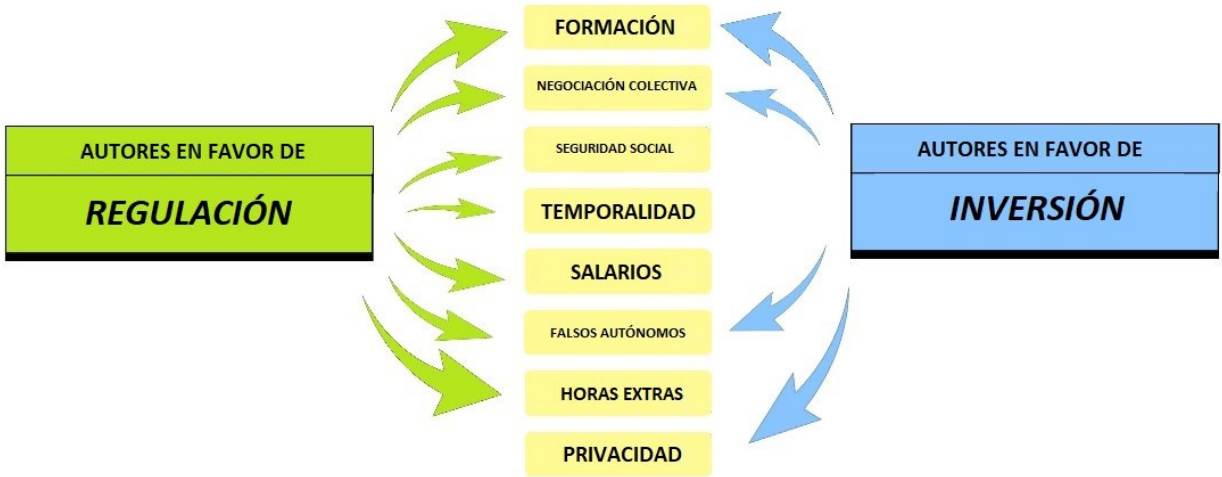

Figura 5. Corrientes de la literatura jurídica y distintas propuestas resolutivas. Fuente: elaboración propia

Por último, es preciso hacer referencia a la negociación colectiva como uno de los principales remedios en la que la mayoría de la literatura legal ${ }^{66}$ y actores sindicales coinciden de cara a resolver este problema de los trabajadores autónomos. Sin embargo, a pesar de ser un derecho reconocido en el artículo 28 de la Carta de los Derechos Fundamentales de la UE, en la mayoría de los países en la Unión Europea existen manifiestas barreras (especialmente debido a la naturaleza de su contrato, de la plataforma y de las limitaciones en materia de competencia que existen en cada uno de los estados) que implican que las personas que trabajan por cuenta propia no pueden llevar a cabo negociaciones colectivas ni ser acomodadas por sindicatos tradicionales ni asociaciones de empleadores ${ }^{67}$.

\section{Conclusiones}

A modo de conclusión, hasta ahora es posible resaltar con seguridad cuatro premisas claras: la primera consiste en la manifiesta inexistencia de un marco regulatorio común a nivel europeo de la economía colaborativa y de las relaciones entre los actores implicados (especialmente los trabajadores); la segunda es la inexistencia de cualquier tipo de esta normativa a nivel de los estados miembros (excepto en Francia que, a pesar de que no hayan sido incluidos los trabajadores autónomos, han sido integradas distintas garantías en la normativa laboral); la tercera son los evidentes conflictos que provocan estas lagunas legales en los estados y que son los Tribunales los llamados a resolverlos a

${ }^{66}$ NewlandS, G., LutZ, C. Y Fieseler, C: "The conditioning function of rating mechanisms for consumers in the sharing economy”, Internet Research, Vol. 29, núm. 5, p. 1090-1108. También Mo, P. y COULSON, N.: "Empowering processes in online support groups among people living with HIV/AIDS: A comparative analysis of 'lurkers' and 'posters"', Computers in Human Behavior, Vol. 26, núm. 5, 2010, p. 1183-1193, en https://www.sciencedirect.com/science/article/pii/S0747563210000683.

${ }^{67}$ Newlands, G., LutZ, C. Y Fieseler, C.: "The conditioning function of rating mechanisms for consumers in the sharing economy", cit., p. 253. 
golpe de sentencia; y la cuarta son las manifiestas alertas y advertencias proyectadas desde las propias instituciones europeas y la doctrina, que invitan a regular esta problemática.

Como señala la propia Comisión Europea, "la fragmentación reglamentaria resultante de enfoques reguladores divergentes a nivel nacional o local (...) dificulta el desarrollo de la economía colaborativa en Europa e impide la plena materialización de sus beneficios" ${ }^{\prime 68}$. Ha sido probado que los países que han tomado medidas para eliminar las barreras del mercado se encuentran en una posición más beneficiosa de desarrollo de este modelo de negocio (República Checa, Francia) y por el contrario "cuando los gobiernos son más bien neutrales y el entorno empresarial no es tan alentador, la economía colaborativa parece desarrollarse a un ritmo más lento" (Bulgaria, Eslovenia) ${ }^{69}$.

Por ello puede afirmarse, con claridad, que una regulación o unas pautas comunes de actuación de los actores en la economía colaborativa a nivel europeo y estatal no solo es necesario, sino que supondría un positivo impacto en los resultados de las empresas, que verían reducidos los conflictos al verse equilibrados los derechos de los actores implicados.

Para ello, una eficaz herramienta resulta una estrategia común de los estados miembros en la economía colaborativa (ya defendidas por parte de algunos eurodiputados -MEPsen el Parlamento Europeo ${ }^{70}$ ) aprobada por la Comisión Europea o el Consejo de Europa. Este tipo de herramientas, muy eficaces en otras ocasiones para coordinar objetivos comunes y plazos para determinadas acciones concretas (algunos ejemplos de resultados eficaces son la Estrategia de la UE en materia de droga 2005- 2012, Estrategia de la Unión Europea para un desarrollo sostenible de 2001 o Estrategia de la UE de lucha contra el terrorismo de 2005), pueden servir para identificar los ámbitos prioritarios en los que los Estados miembros deben intensificar sus esfuerzos para lograr objetivos de avance y garantía en los derechos de los agentes participes de este modelo de negocio.

Esta Estrategia Europea de Economía colaborativa debería incluir las medidas sugeridas por parte de las instituciones a los países miembros y las aportadas por parte de la doctrina. En este sentido, resultaría transcendental incluir medidas de la Comisión

\footnotetext{
${ }^{68}$ COMISIÓN EuROPEA: Study to Monitor the Economic Development of the Collaborative Economy at sector level in the 28 EU Member States, cit., pág. 2.

${ }^{69}$ COMISIÓN EUROPEA: Study to Monitor the Economic Development of the Collaborative Economy at sector level in the 28 EU Member States, cit. , pág. 159.

${ }^{70}$ Como el eurodiputado Nicola Danti., PARLAMEnTo Europeo: "Economía colaborativa: el Parlamento pide directrices claras de la UE", 2017, en http://www.europarl.europa.eu/news/en/pressroom/20170609IPR77014/sharing-economy-parliament-calls-for-clear-eu-guidelines
} 
Europea relativas a: garantizar que tanto los trabajadores como los trabajadores autónomos tienen acceso efectivo a las protecciones sociales; conservar y mantener adecuadamente los mecanismos reputacionales o desarrollar mecanismos que permitan la transparencia y derecho a la información y replica en los mecanismos reputacionales por gozar estos de trascendental importancia, entre otras. También deben incluirse recomendaciones defendidas por el parlamento europeo y sus estudios por él encargados como: la introducción de requisitos mínimos de salario e ingresos; el aumento de las inspecciones laborales sobre las plataformas digitales; aumentar la cobertura de los convenios colectivos a categorías que van más allá de la de empleado ordinario o introducir el debate de revertir la carga de la prueba en los procedimientos de clasificación del contrato de trabajo; introducir que sea una autoridad independiente la que garantice que la calificación de la naturaleza del contrato (como ocurre en algunos países miembros), entre otras.

Por ello el presente estudio propone el necesario desarrollo de una Estrategia Europea de Economía Colaborativa que contemple todos estos extremos, de tal forma que disminuyan las amenazas sobre algunos de los actores implicados, sean equilibrados todos los derechos en juego y, por ende, finalmente la economía colaborativa reporte a toda Europa los probados beneficios que refleja sin suponer ningún riesgo o amenaza.

\section{Bibliografía}

BAYlos, A.: "El futuro de las normas del trabajo que queremos", Blog: Plataforma Digital Interuniversitaria sobre el Futuro del Derecho del Trabajo OIT [en línea], [Fecha de consulta: 20/10/2019], disponible en: https://iniciativaoitinteruniversitariafuturodeltrabajo.com/ver-articulos/item/el-futurode-las-normas-del-trabajo-que-queremos.

BBC News: "GMB union holds protests at Amazon sites”, Web: BBC News [en línea], [Fecha de consulta: 20/10/2019], disponible en: https://www.bbc.com/news/uk21444710

BERG, J.: "Income security in the on-demand economy: Findings and policy lessons from a survey of crowdworkers", OIT, Ginebra, 2016, en https://www.ilo.org/wcmsp5/groups/public/---ed_protect/---protrav/--travail/documents/publication/wcms_479693.pdf.

BRIGAND, M.: “Quand Amazon s'arrange avec les accidents de travail”, Web: Le Figaro [en línea], [Fecha de consulta: 20/10/2019], disponible en: 
http://www.lefigaro.fr/secteur/high-tech/2015/05/22/32001-20150522ARTFIG00258quand-amazon-s-arrange-avec-les-accidents-de-travail.php?redirect_premium

BоотH, R.: "Low-paid workers need better job satisfaction, No 10 review will say", Web: The Guardian [en línea], [Fecha de consulta: 20/10/2019], disponible en: https://www.theguardian.com/society/2017/jul/07/low-paid-workers-job-satisfactionno-10-review-taylor-report

BоотH, R.: "Gig economy workers angry at lack of bogus self-employment curbs", Web: The Guardian [en línea], [Fecha de consulta: 20/10/2019], disponible en: https://www.theguardian.com/business/2018/feb/07/gig-economy-workers-angry-atlack-of-bogus-self-employment-curbs

Bollettino Ufficiale Della Regione Umbria: "Proposta di legge alle camere 'Disposizioni in materia di lavoro mediante piattaforme digitali'”, 2019, en https://inapp.org/sites/default/files/NORMATIVA/2019/Regionale/UM_DAL\%20n.315 \%20del\%2019-03-19.pdf

CHERry, M.: "Beyond Misclassification: The Digital Transformation of Work", Comparative Labor Law \& Policy Journal, 2016, Vol. 37, págs. 577-602, en https://scholarship.law.slu.edu/cgi/viewcontent.cgi?article=1009\&context=faculty.

Codagnone, C., ABAdie, F. Y Biagi, F.: The Future of Work in the 'Sharing Economy', Market Efficiency and Equitable Opportunities or Unfair Precarisation, Comisión Europea, $\quad$ Bruselas, 2016, en http://publications.jrc.ec.europa.eu/repository/bitstream/JRC101280/jrc101280.pdf.

COMISIÓN EUROPEA: Comunicación de la comisión al parlamento europeo, al consejo, al comité económico y social europeo y al comité de las regiones; una agenda europea para la economía colaborativa, 2016, https://eur-lex.europa.eu/legalcontent/EN/TXT/HTML/?uri=CELEX:52016DC0356\&from=ES.

COMISIÓN EuROPEA: Study to Monitor the Economic Development of the Collaborative Economy at

sector level in the 28 EU Member States, 2018, en https://publications.europa.eu/en/publication-detail/-/publication/0cc9aab6-7501-11e89483-01aa75ed71a.

COMision EuropeA, Second Phase Consultation of Social Partners under Article 154 TFEU on a possible action addressing the challenges of access to social protection for 
people in all forms of employment in the framework of the European Pillar of Social Rights, 2017, en https://ec.europa.eu/social/BlobServlet?docId=18596\&langId=en.

Comisión EuropeA, Commission Staff Working Document, Analytical Document, Accompanying the document Consultation Document (Second Phase Consultation of Social Partners under Article 154 TFEU on a possible action addressing the challenges of access to social protection for people in all forms of employment in the framework of the European Pillar of Social Rights), 2017, en https://ec.europa.eu/social/BlobServlet?docId=18596\&langId=en.

CUNNINGHAM, O.: "TERROR ON STREETS Deliveroo riders strike in Dublin to protest recent spate of violent assaults by teenagers”, Web: The Sun [en línea], [Fecha de consulta: 20/10/2019], disponible en: https://www.thesun.ie/news/3787988/deliveroo-riders-strike-dublin-attacks/

DøLVIK, J.E. Y JESNES. K.: Nordic labour markets and the sharing economy, Nordic Council of Ministers, Dinamarca, 2017, en https://norden.divaportal.org/smash/get/diva2:1072087/FULLTEXT02.pdf.

Gozzer, S.: "Trabajo dice que los chóferes de Uber son empleados de la firma", Web: El Pais [en línea], [Fecha de consulta: 20/10/2019], disponible en: https://elpais.com/economia/2015/06/12/actualidad/1434135569_865496.html

DePARTMENT For Business, ENERGy \& InDUSTRIAl Strategy, Good work plan, 2018, en

https://assets.publishing.service.gov.uk/government/uploads/system/uploads/attachment _data/file/766167/good-work-plan-command-paper.pdf

DEPARTMENT For Business, ENERGy \& InDUSTRIAL STRATEgy, Largest upgrade in a generation to workplace rights - getting work right for British workers and businesses, 2018, en https://www.gov.uk/government/news/largest-upgrade-in-a-generation-toworkplace-rights-getting-work-right-for-british-workers-and-businesses.

Europa Press: "El PP lleva al Pleno del Congreso la precariedad de los 'falsos autónomos' en empresas como Deliveroo", Web: Europa Press [en línea], [Fecha de consulta: 20/10/2019], disponible en: https://www.europapress.es/economia/laboral00346/noticia-pp-1leva-pleno-congreso-precariedad-falsos-autonomos-empresasdeliveroo-20180621150238.html 
HASBERG, M.: “Gewerkschaft klagt über Lohndumping bei Amazon”, Web: Welt [en línea], [Fecha de consulta: 20/10/2019], disponible en: https://www.welt.de/wirtschaft/article11688472/Gewerkschaft-klagt-ueberLohndumping-bei-Amazon.html.

HASWELL, J.: "Foodora and Deliveroo couriers protest working conditions in Berlin", Web: The Local [en línea], [Fecha de consulta: 20/10/2019], disponible en: https://www.thelocal.de/20170518/foodora-and-deliveroo-couriers-protest-workingconditions-in-berlin

Huws, U., Spencer, N. H. Y Syrdal, D.: "Online, on call: the spread of digitally organised just-in-time working and its implications for standard employment models", New Technology, Work and Emplyment, Vol. 33, núm. 8, 2018, págs. 113-129, en https://uhra.herts.ac.uk/bitstream/handle/2299/20891/Huws_et_al_2018_New_Technolo gy_Work_and_Employment.pdf?sequence $=1$ \&isAllowed $=\mathrm{y}$

INFORMATION TECHNOLOGY AND INNOVATION FOUNDATION: "Three Paths to Update Labor Law for the Gig Economy", Information Technology \& Innovation Foundation, Washington, 2016, en http://www2.itif.org/2016-labor-law-gigeconomy.pdf?_ga=2.219725593.1271927154.1554598313-1835988216.1554598313

LA VANGUARDIA: "PP, PSOE y Cs piden estudiar con sindicatos y patronal cómo adaptar la ley laboral a la economía digital", Web: La Vanguardia [en línea], [Fecha de consulta: 20/10/2019], disponible en: https://www.lavanguardia.com/vida/20180626/45424884357/economia--pp-psoe-y-cspiden-estudiar-con-sindicatos-y-patronal-como-adaptar-la-ley-laboral-a-la-economiadigital.html

LEHMANN, H: "Fahrradkuriere von Deliveroo und Foodora stellen Forderungen", Web: Tagesspiegel [en línea], [Fecha de consulta: 20/10/2019], disponible en: https://digitalpresent.tagesspiegel.de/fahrer-von-foodora-und-deliveroo-organisierensich

MANDL, I. et alii: New forms of employment, Publications Office of the European Union, Luxemburg, 2015, en https://www.eurofound.europa.eu/sites/default/files/ef_publication/field_ef_document/e f1461en.pdf 
MATSAGANIS, M. et alii: Non-standard employment and access to social security benefits, Comisión Europea, Bruselas, 2016, en http://ec.europa.eu/social/BlobServlet?docId=15687\&langId=en.

McdonAlD, P. Y THOMPSON, P.: "Social Media(tion) and the Reshaping of Public/Private Boundaries in Employment Relations", International Journal of Management Reviews, Vol. 18, núm. 1, 2015, págs. 69-84, en https://onlinelibrary.wiley.com/doi/epdf/10.1111/ijmr.12061

Mo, P. Y COULSON, N.: "Empowering processes in online support groups among people living with HIV/AIDS: A comparative analysis of 'lurkers' and 'posters", Computers in Human Behavior, Vol. 26, núm. 5, 2010, págs. 1183-1193, en https://www.sciencedirect.com/science/article/pii/S0747563210000683.

MOYER-LeE, J.: "Wishy-washy and full of fluff - the Taylor review offers Little", Web: The Guardian [en línea], [Fecha de consulta: 20/10/2019], disponible en: https://www.theguardian.com/commentisfree/2017/jul/18/taylor-review-gig-economyworkers.

Newlands, G., Lutz, C. Y FieSELER, C.: "The conditioning function of rating mechanisms for consumers in the sharing economy", Internet Research, Vol. 29, núm. 5, 2019, págs. 1090-1108.

RochA, F.: "La Digitalización y el Empleo Decente en España: Retos y propuestas de actuación", Blog: Plataforma Digital Interuniversitaria sobre el Futuro del Derecho del Trabajo OIT [en línea], [Fecha de consulta: 20/10/2019], disponible en: https://www.ilo.org/madrid/fow/trabajo-decente-para-todos/WCMS_548595/lang-es/index.htm.

Rodríguez Fernández, M.L., Y PÉRez Del Prado, D.: Economía digital: su impacto sobre las condiciones de trabajo y empleo. Estudio de caso sobre dos empresas de base tecnológica, Fundación para el Diálogo Social, Madrid, 2017, en http://fdialogosocial.org/public/upload/2/23_FdS_Economia-digital-impactocondiciones-trabajo-y-empleo_2017_final.pdf.

REUTERS: "Verdi funkt Amazon im Weihnachtsgeschäft mit Streik dazwischen", Reuters [en línea], [Fecha de consulta: 20/10/2019], disponible en: https://de.reuters.com/article/deutschland-amazon-idDEKBN1OG0U1 
SANSOM, A.: "Bicycle couriers protest against takeaway food service Deliveroo", Web: France 24 [en línea], [Fecha de consulta: 20/10/2019], disponible en: https://www.france24.com/en/20170812-france-paris-protest-food-delivery-servicedeliveroo-financial-insecurity-emmanuel-macron

Sentencia del Tribunal de Apelación (División Civil) sobre la apelación del Tribunal de Empleo del Reino Unido, 10 de Febrero de 2017 (Pimlico Plumbers y Anor vs. Smith), en https://www.employmentcasesupdate.co.uk/site.aspx?i=ed35083

PARlamento EuropeO: "Resolución del Parlamento Europeo, de 19 de enero de 2017, sobre un pilar europeo de derechos sociales", 2017, en http://www.europarl.europa.eu/sides/getDoc.do?pubRef=-//EP//TEXT+TA+P8-TA2017-0010+0+DOC+XML+V0//EN.

PARLAMENTO EUROPEO: Informe sobre una Agenda Europea para la economía colaborativa, 2017, en http://www.europarl.europa.eu/doceo/document/A-8-20170195_EN.pdf.

Peter, L.: "No plans to expand Finland basic income trial", Web: BBC [en línea], [Fecha de consulta: 20/10/2019], disponible en: https:/www.bbc.com/news/worldeurope-43866700

PRASSL, J. Y RISAK, M.: “Uber, Taskrabbit, \& Co: Platforms as Employers? Rethinking the legal analysis of Crowdwork", Comparative Labor Law \& Policy Journal, Vol. 37 , núm. 3, 2016, págs. 604-619.

PoliTI, J: “Di Maio takes aim at Italy's gig economy”, Web: Financial Times [en línea], [Fecha de consulta: 20/10/2019], disponible en: https://www.ft.com/content/04b6d97c7305-11e8-aa31-31da4279a601

PwC, Global Top 100 Companies by market capitalisation, 2017, en https://preview.thenewsmarket.com/Previews/PWC/DocumentAssets/477067.pdf.

REUTERS: "Verdi funkt Amazon im Weihnachtsgeschäft mit Streik dazwischen", Web: Reuters [en línea], [Fecha de consulta: 20/10/2019], disponible en: https://de.reuters.com/article/deutschland-amazon-idDEKBN1OG0U1

SAN MARTín MAZzUCCONI, C.: "Generalización Tecnológica: efectos sobre las condiciones de trabajo y empleo", Blog: Plataforma Digital Interuniversitaria sobre el Futuro del Derecho del Trabajo OIT [en línea], [Fecha de consulta: 20/10/2019], 
disponible en: https://www.ilo.org/wcmsp5/groups/public/---europe/---ro-geneva/---ilomadrid/documents/article/wcms_548618.pdf.

SÁNCHEZ-URÁn AZAÑA, Y. Y GRAU RUIZ, M.A.: "El impacto de la robótica, en especial la robótica inclusiva, en el trabajo: aspectos jurídico-laborales y fiscales", Blog: Plataforma Digital Interuniversitaria sobre el Futuro del Derecho del Trabajo OIT [en línea], [Fecha de consulta: 20/10/2019], disponible en: https:/iniciativaoitinteruniversitariafuturodeltrabajo.com/ver-articulos/item/el-impactode-la-robotica-en-especial-la-robotica-inclusiva-en-el-trabajo-aspectos-juridicolaborales-y-fiscales.

Sentencia del Tribunal de Empleo del Centro de Londres, 21 de marzo de 2017, (Boxer vs. Excel Group Services Ltd), en https://assets.publishing.service.gov.uk/media/58ecacb5ed915d06ac000150/Mr_A_Box er_v_Excel_Group_Services_Ltd_in_liquidation_32003652016_Final_and_Reasons.pdf

Sentencia del Tribunal de Apelación (División Civil) sobre la apelación del Tribunal de Empleo del Reino Unido, 30 de octubre de 2018 (Uber B.V. \& Ors v Aslam \& Ors), en http://www.bailii.org/ew/cases/EWCA/Civ/2018/2748.html

SeRvulo GonZAlez, J.: "Hacienda pretende gravar más a plataformas como Airbnb y Uber", Web: El Pais [en línea], [Fecha de consulta: 20/10/2019], disponible en: https://elpais.com/economia/2018/10/04/actualidad/1538646576_607775.html

SCHMID-DRÜNER, M.: "The situation of workers in the collaborative economy", Parlamento Europeo, Bruselas, 2016, en http://www.europarl.europa.eu/RegData/etudes/IDAN/2016/587316/IPOL_IDA(2016)5 87316_EN.pdf.

SHENKER, J: "Strike 2.0: how gig economy workers are using tech to fight back", Web: The Guardian [en línea], [Fecha de consulta: 20/10/2019], disponible en: https://www.theguardian.com/books/2019/aug/31/the-new-resistance-how-gigeconomy-workers-are-fighting-back.

Spasova, S. et alii: Access to social protection for people working on non-standard contracts and as self-employed in Europe, Comisión Europea, Bruselas, 2017, en https://publications.europa.eu/en/publication-detail/-/publication/fb235634-e3a7-11e79749-01aa75ed71a1/language-en. 
SPONHOLZ, K.: "Beschäftigte beklagen mieses Arbeitsklima bei Amazon", Web: Westfälische Rundschau, [en línea], [Fecha de consulta: 20/10/2019], disponible en: https://www.wr.de/region/westfalen/beschaeftigte-beklagen-mieses-arbeitsklima-beiamazon-id7064258.html

SINGH, A.: "Deliveroo agrees to pay workers $£ 7$ an hour after wage protests", Web: The Independent [en línea], [Fecha de consulta: 20/10/2019], disponible en: https://www.independent.co.uk/news/business/news/deliveroo-wages-protests-agreesto-pay-workers-7-an-hour-after-protests-against-wages-overhaul-a7190071.html

STROKES, K. et alii: Making sense of the UK Collaborative Economy, Nesta, Londres, 2014, en https:/collaborativeeconomy.com/wp/wpcontent/uploads/2015/04/making_sense_of_the_uk_collaborative_economy_14.pdf

SWINFORD, S.: "Theresa May paves way for self-employed and temporary workers to be protected by new laws", Web: The Telegraph [en línea], [Fecha de consulta: 20/10/2019], disponible en: https://www.telegraph.co.uk/news/2016/09/30/theresa-maypaves-way-for-self-employed-and-temporary-workers-to/

TASSINARI A. Y MACCARRONE, V: "The mobilisation of gig economy couriers in Italy: some lessons for the trade union movement", Transfer, Vol. 23, 2017, núm. 3, págs. 353-357.

Todolí Signes, A.: “El impacto de la 'uber economy' en las relaciones laborales: los efectos de las plataformas virtuales en el contrato de trabajo", Iuslabor, núm. 3, 2015, págs. 1699-2938.

UGT: "Denuncia de UGT sobre plataformas digitales en Dirección General de Trabajo", 2017, en http://www.ugt.es/Publicaciones/denuncia\%20plataformas\%20digitales.pdf

VALENDUC, G Y VENDRAMIN, P.: Work in the digital economy: sorting the old from the new, Instituto Sindical Europeo, Bruselas, 2016, pág. 46.

VION-DURY, P: “Tu travailles à Amazon? Oh, mon pauvre. Tu tiens le coup?", Web: Nouve Lobs [en línea], [Fecha de consulta: 20/10/2019], disponible en: https://www.nouvelobs.com/rue89/rue89-economie/20140320.RUE2786/tu-travailles-aamazon-oh-mon-pauvre-tu-tiens-le-coup.html.

VOSS, E. Y RIEDE H.: “Cyfryzacja A Partycypacja Pracowników: Jakie są opinie związków zawodowych, pracowników na poziomie przedsiębiorstwa i pracowników 
wykonujących pracę za pośrednictwem platform cyfrowych w Europie”, Confederación $\begin{array}{lllll}\text { Europea de } & \text { Sindicatos, } & \text { Bruselas, } & \text { 2018, }\end{array}$ https://www.etuc.org/sites/default/files/publication/file/201809/Voss\%20Report\%20PL1.pdf 